\title{
Parâmetros hematológicos e bioquímicos da tilápia-do-Nilo (Oreochromis niloticus L.) sob estresse por exposição ao ar $^{1}$
}

\author{
Roberta Dias da Silva ${ }^{2 *}$, Laudicéia Oliveira Rocha ${ }^{3}$, Bruno Duarte Alves Fortes ${ }^{3}$, \\ Dirson Vieira ${ }^{2}$ e Maria Clorinda Soares Fioravanti ${ }^{2}$
}

\begin{abstract}
Silva R.D., Rocha L.O., Fortes B.A.D., Vieira D. \& Fioravanti M.C.S. 2012. [Hematological parameters of Nile Tilapia (Oreochromis niloticus L.) under air exposure stress.] Parâmetros hematológicos da tilápia-do-Nilo (Oreochromis niloticus L.) sob estresse por exposição ao ar. Pesquisa Veterinária Brasileira 32(Supl.1):99-107. Setor de Patologia, Escola de Veterinária e Zootecnia, Universidade Federal de Goiás, Campus Samambaia, Cx. Postal 131, Goiânia, G0 74001-970, Brazil. E-mail: diasroberta5@gmail.com

The present study evaluated the hematological and biochemical parameters of adult tilapia (Oreochromis niloticus) under the influence of the physiological stress factor in animals submitted to air exposure during fattening in raceway system. Blood cell count, hemoglobin, hematocrit, mean corpuscular volume (MCV), mean corpuscular hemoglobin (MCH), mean corpuscular hemoglobin concentration (MCHC), leukogram, differencial leukocyte count, platelet, glucose, total protein, cholesterol, triglycerides and electrolytes (calcium, chloride, sodium and potassium) were analyzed. The results showed a uniform distribution for red blood cells, hematocrit, hemoglobin, secondary Wintrobe indices, total protein, glucose, cholesterol, and serum ions, indicated by a relatively low variation coefficient. There was positive correlation only for total white blood cells, organic defense cells (neutrophils and lymphocytes), glucose, cholesterol, sodium and calcium. As for the leukocytes (WBC), as the animals were exposed to aeration, the number of leukocytes gradually decreased (leukopenia), simultaneously occurring neutrophilia and lymphopenia. The glycemic index was a good indicator of physiological stress due to hyperglycemia $(82.0 \pm 20.88 \mathrm{mg} / \mathrm{dL})$ demonstrated in the treatments. The air exposure constituted an imbalance factor at the ion homeostasis and at the endogenous cholesterol synthesis. Besides, the recovery time did not result in the complete physiological rehabilitation face the imposed challenge.
\end{abstract}

INDEX TERMS: Nile tilapia, Oreochromis niloticus, stress, hematology, fish.

RESUMO.- No presente trabalho avaliaram-se os parâmetros hematológicos e bioquímicos de exemplares adultos de tilápias (Oreochromis niloticus) sob a influência do fator estresse fisiológico em animais submetidos à exposição ao ar durante a engorda em sistema raceway. Foram analisados o eritrograma, teor de hemoglobina, volume globular, o volume corpuscular médio (VCM), a hemoglobina corpuscular média (HCM), a concentração de hemoglobina

\footnotetext{
${ }^{1}$ Recebido em 6 de outubro de 2012.

Aceito para publicação em 5 de novembro de 2012

${ }^{2}$ Setor de Patologia, Escola de Veterinária e Zootecnia (EVZ), Universidade Federal de Goiás (UFG), Campus Samambaia, Rodovia Goiânia - Nova Veneza, Cx. Postal 131, Goiânia, GO 74001-970, Brasil. *Autor para correspondência: diasroberta5@gmail.com

${ }^{3}$ Departamento de Produção Animal, EVZ-UFG, Cx. Postal 131, Goiânia, GO 74001-970.
}

corpuscular média (CHCM), o leucograma, contagem diferencial de leucócitos, o plaquetograma, a glicose, a proteína total, o colesterol, o triglicerídeo e os eletrólitos (cálcio, cloretos, sódio e potássio). Os resultados revelaram que houve uma homogeneidade de distribuição para hemácias, volume globular, hemoglobina, índices hemantimétricos, proteína total, glicose, colesterol, e íons séricos, indicados pelos valores relativamente baixos do coeficiente de variação. Houve correlação positiva somente para leucócitos totais, células de defesa orgânica (neutrófilos e linfócitos), glicose, colesterol, sódio e cálcio. Quanto ao leucograma, à medida que os animais foram expostos ao ar, o número de leucócitos diminuiu gradativamente (leucopenia), ocorrendo simultaneamente neutrofilia e linfopenia. 0 índice glicêmico constituiu um bom indicador de estresse fisiológico, devido à hiperglicemia $(82,0 \pm 20,88 \mathrm{mg} / \mathrm{dL})$ demonstrada 
nos tratamentos. A exposição ao ar constituiu um fator de desequilíbrio na homeostase iônica, e na síntese de colesterol endógeno. Entretanto, o tempo de recuperação não ocasionou a completa reabilitação fisiológica frente ao desafio imposto.

TERMOS DE INDEXAÇÃO: Tilápia-do-Nilo, Oreochromis niloticus, estresse, hematologia, peixes.

\section{INTRODUÇÃO}

A aquicultura brasileira tem se desenvolvido muitos nos últimos anos, inclusive se impondo como uma nova atividade pecuária. 0 crescimento médio mundial dessa atividade na última década foi cinco vezes maior quando comparada com outras atividades do setor, tais como a bovinocultura, a suinocultura e a avicultura. No Brasil, a aquicultura tem se firmado cada vez mais com caráter profissionalizante, em decorrência dos recursos hídricos disponíveis, clima favorável, mão de obra relativamente barata e crescente mercado interno.

Somente no ano de 2009, a produção de pescado no Brasil foi de aproximadamente de 1,240milhões de toneladas, sendo que 825 mil foram provenientes da pesca enquanto que, aproximadamente 415 mil foram oriundos da aquicultura. Atualmente, o Brasil é o sexto maior produtor de tilápia cultivada no mundo e a tilápia-do-Nilo (Oreochromis niloticus), sozinha, respondeu pela oferta de 132 mil de toneladas em 2009, o que representou aproximadamente $39 \%$ da produção total de pescados em aquicultura de água doce (Brasil 2010).

A eficiência da aquicultura intensiva depende da máxima utilização dos recursos hídricos. As densidades de estocagem devem ser as mais altas possíveis, sem afetarem o crescimento, o ganho de peso e a resistência às doenças. Uma característica importante da piscicultura brasileira é o grande número de espécies criadas. Hoje, utilizam-se mais de 30 espécies, com os mais variados hábitos alimentares e ambientes de vida (Scorvo-Filho 2003). No entanto, observa-se que as principais espécies cultivadas no país são de origem exótica (tilápia, carpa e bagre americano).

A tilápia-do-Nilo é considerada um exemplar exótico por ser procedente da Costa do Marfim, e foi introduzida inicialmente no Brasil pelo Departamento Nacional de Obras Contra as Secas (DNOCS), em 1971. Trata-se de uma espécie onívora que aceita com facilidade vários tipos de alimento, dócil ao manejo em todas as fases de cultivo, boa rusticidade, prolífica e de fácil domínio da reprodução precoce, com alta qualidade de carne-filé (Tavares-Dias et al. 2000b).

Uma das principais características fisiológicas desses animais é a sua resistência a enfermidades por patógenos, assim como a tolerância a baixos teores de oxigênio dissolvido na água. Seu melhor desempenho produtivo é obtido em temperatura aquática entre $26^{\circ} \mathrm{C}$ e $28^{\circ} \mathrm{C}$. E ao abate, consegue-se obter filés de excelente qualidade, que correspondem a $37 \%$ da carcaça (600g peso total do peixe) e tem como peculiaridade a ausência de espinhos em sua carne, e apresenta sabor bastante atrativo ao paladar (Souza \& Maranhão 2001).
Segundo Iwama (1993), em produções intensivas de peixes, o estresse dos animais é praticamente inevitável. 0 estresse ocorre de duas maneiras diferentes, sendo importante diferenciá-las, o estresse agudo e o estresse crônico. 0 primeiro geralmente acontece durante o manejo dos animais, como no transporte ou durante a realização de biometrias, que leva os peixes a um estresse rápido. 0 segundo tipo de estresse é o crônico, em que as consequências geralmente são a redução do crescimento e ganho de peso, queda da resistência a patógenos, devido à resposta imunológica deprimida. Acontece em condições que mantêm os peixes permanentemente estressados, devido a agentes estressores de natureza química, como o pH incorreto, baixo nível de oxigênio dissolvido na água, concentração elevada de amônia (Moraes et al. 2004) e nitrito (Costa et al. 2004), decorrentes da degradação da matéria orgânica, poluentes orgânicos e inorgânicos (Carvalho \& Fernandes 2006), ou podem ser de natureza física, como a alta densidade populacional, confinamento e captura.

Dentre os indicadores de estresse animal, o cortisol plasmático é o indicador mais largamente utilizado em peixes, qualquer que seja o seu estágio de desenvolvimento (Wendelaar Bonga 1997). 0 cortisol em peixes atua via dois tipos de frações, mineralocorticóides e glicocorticóides. Em sua função mineralocorticóide, o cortisol atua na regulação osmótica e iônica; enquanto que na função como glicocorticóide, ele estimula a glicogenólise e a gliconeogênse hepática (Pickering 1981, Wendelaar Bonga 1997). Dessa forma, a glicose tem sido empregada rotineiramente como indicador de estresse, e os níveis basais de peixes teleósteos podem ser facilmente detectados (Silva et al. 2009).

A avaliação imunológica também constitui um bom parâmetro de avaliação, uma vez que, após a liberação de hormônios glicocorticóides, quer seja endógeno ou exógeno, se reflete de forma quantitativa sobre os leucócitos (Rijnberk \& Mol 1997). Devido à ação modeladora do cortisol ocorre uma diminuição da atividade fagocitária e da migração de leucócitos para a região inflamada. Observa-se concomitantemente neutrofilia e linfopenia, em que o aumento de neutrófilos se deve a diminuição na migração de neutrófilos para o compartimento tecidual (diapedese), e aumento do seu tempo na circulação, ou seja, um desvio do compartimento marginal para o circulante. Já a diminuição de linfócitos se deve pela redistribuição dos linfócitos circulantes, com sequestro nos tecidos linfóides e medula óssea, assim como pela lise de alguns tipos de linfócitos nos linfonodos (Mazeaud et al. 1977, Rijnberk \& Mol 1997). A trombocitose (aumento do número de trombócitos ou plaquetas) ocorre devido à contração esplênica, em que o baço sequestra de $1 / 4$ a $2 / 3$ do total de plaquetas para o compartimento circulante, o que resulta também no aumento do volume globular.

Embora haja literatura sobre a hematologia e bioquímica de teleósteos, pouco ou quase nada se conhece sobre a influência de estresse por exposição ao ar na fisiologia da espécie exótica avaliada em questão. Desse modo, informações e conhecimentos sobre suas variáveis hematológicas e bioquímicas podem proporcionar relevantes indicações de alterações em seu estado fisiológico ao piscicultor. 
Nesse sentido, objetivou-se comparar os parâmetros sanguíneos e bioquímicos da tilápia-do-Nilo submetidas à exposição ao ar durante a engorda em viveiros artificiais, e a influência do tempo de exposição como fator de estresse fisiológico dos animais, assim como o tempo de recuperação dos mesmos.

\section{MATERIAL E MÉTODOS}

O experimento foi conduzido no Setor de Piscicultura do Departamento de Produção Animal da Escola de Veterinária e Zootecnia da Universidade Federal de Goiás (DPA/EVZ/UFG), em dezembro de 2009, com duração aproximada de 15 dias. Foram utilizados 64 exemplares adultos de tilápia-do-Nilo (Oreochromis niloticus) com peso médio de $340 \mathrm{~g}$, os quais foram distribuídos aleatoriamente em oito caixas d'água de polietileno de 1000L. A densidade populacional empregada para cada caixa foi de dez peixes. Todos os procedimentos adotados na condução deste experimento foram aprovados pelo Comitê de Ética da Instituição - 114/2009.

Os animais foram mantidos em sistema de criação do tipo raceway, que consiste na utilização de alto volume de troca de água, ou seja, fluxo intenso. Foram empregadas caixas d'água de polietileno com volume máximo de 1000L por caixa, providas de fluxo individual de água na proporção de $960 \mathrm{~L} / \mathrm{h}$, com registros e tubulações que permitem controlar a vazão de água de abastecimento, e com sistema de escoamento instalado no fundo de cada caixa, o que permite o auto-sinfonamento dos resíduos depositados. Antes da realização das atividades, as caixas foram lavadas e enxaguadas, colocadas sob o sol e em seguida receberam a aplicação de sal comum nas suas paredes internas. As caixas d'água encontraram-se instaladas a céu aberto e com acesso restrito ao local, sendo protegidas com arandela de arame para evitar o ataque de pássaros e outros possíveis predadores.

Os animais selecionados foram oriundos do próprio sistema de produção do Setor de Piscicultura - EV/UFG, coletados animais por meio de captura com rede de arrastão. Após a captura, os animais foram pesados para a obtenção de homogeneidade da população a ser analisada durante o ensaio.

Os peixes foram alimentados com ração extrusada comercial (32\% de proteína bruta) com seis a oito $\mathrm{mm}$ de diâmetro duas vezes ao dia, às $9 \mathrm{~h}$ e $17 \mathrm{~h}$, durante todo o experimento. A dieta foi fornecida ad libitum e suspensa 12 horas antes do início das atividades com as exposições ao ar e a colheita das amostras.

0 delineamento empregado no experimento foi o inteiramente casualizado (DIC), em que os animais foram distribuídos em oito caixas d'água de polietileno, sendo que cada caixa constituiu uma unidade experimental, o que totalizou oito tratamentos:

\section{C - controle;}

E30' - exposição por meia hora;

E60' - exposição por uma hora;

E90' - exposição por uma hora e meia;

E60'R30' - uma hora de exposição e meia hora de recuperação;

E60'R90' - uma hora de exposição e uma hora e meia de recuperação;

E90'R30' - uma hora e meia de exposição e meia hora de recuperação;

E90'R90' - uma hora e meia de exposição e uma hora e meia de recuperação.

Para promover a exposição ao ar dos animais foi adotado o seguinte procedimento: após o período de adaptação de aproximadamente 15 dias, inicialmente foi fechado o fluxo individual de entrada de água nas caixas, seguida pela remoção de água por sifonamento, que acarretou na diminuição do nível de água dentro das caixas, e consequentemente, da quantidade de oxigênio disponível. A água das caixas foi lentamente removida para promover a exposição ao ar por períodos diferenciados de tempo por meio de um sifão para não causar distúrbios aos animais. Uma fina camada de água de aproximadamente cinco $\mathrm{cm}$ foi deixada no fundo da caixa para manter a umidade do ambiente e evitar a dessecação, o que caracterizou o período de exposição.

Para as avaliações de recuperação, as caixas foram acrescidas novamente de água por meio da abertura do fluxo individual para elevar o nível das caixas, a fim de se estabelecer as condições ambientais anteriores à exposição ao ar.

Para o procedimento de colheita das amostras de oito exemplares por caixa, foi empregado o puçá para a remoção dos animais, seguido pelo acondicionamento em baldes plásticos. $\mathrm{Na}$ caixa destinada ao grupo controle, não ocorreu à exposição ao ar e os animais ficaram expostos somente o tempo necessário para a colheita das amostras, não excedendo um minuto por colheita sanguínea.

Imediatamente após o período de exposição ao ar (E30', E60' e E90'), assim como de controle (C) e recuperação (E60'R30', E60'R90', E90'R30', E90'R90') e a colheita do sangue, os animais foram descartados e encaminhados posteriormente à venda. Ao final, obtiveram-se 64 amostras para análises hematológicas e bioquímicas.

As análises de água das caixas experimentais foram realizadas no Setor de Piscicultura diariamente, sendo observados os seguintes parâmetros: temperatura da água e do ambiente, oxigênio dissolvido, índice de saturação de oxigênio por meio da utilização de oxímetro microprocessado digital - AT 150 da AlfaKit@. A cada dois dias foi mensurada a vazão de cada caixa individualmente. Todos os dados obtidos foram registrados e arquivados para posterior análise, caso necessário.

Os peixes foram acondicionados em balde plásticos de $20 \mathrm{~L}$ antes do procedimento de colheita do sangue, e posterior punção da veia caudal, utilizando seringas descartáveis de cinco $\mathrm{mL}$ sem anticoagulantes. Sendo que, os dois $\mathrm{mL}$ iniciais foram acondicionados e homogeneizados em tubos plásticos previamente identificados, que continham EDTA como anticoagulante para a preservação das amostras destinadas a ensaios hematológicos (Tavares-Dias et al. 2000a, 2001). Os demais três mL da seringa foram armazenados em tubos plásticos sem anticoagulante para a obtenção de soro para as dosagens bioquímicas e tubos com anticoagulante fluoreto de sódio para a determinação de glicose plasmática.

Após a obtenção das amostras, as mesmas foram encaminhadas ao Laboratório Multiusuário do Programa de Pós-Graduação da Escola de Veterinária e Zootecnia, situado no Setor de Medicina Veterinária Preventiva, para o armazenamento e processamento das análises.

O o volume globular (VG em \%) foi determinado por meio da técnica de microhematócrito com capilares heparinizados, segundo a técnica de Goldenfarb et al. (1971). Para a contagem de eritrócitos $(\mathrm{He} / \mu \mathrm{L})$ foi empregada à solução de formol citrato modificada por Oliveira-Junior et al. (2008). A concentração de hemoglobina total $([\mathrm{Hb}]=\mathrm{g} / \mathrm{dL})$ foi determinada a partir da técnica da cianeto hemoglobina, proposta por Collier (1944), com a utilização de reagente comercial Hemoglobina cat. 43 da Labtest Diagnóstica ${ }^{\circledR}$, Lagoa Santa, MG. A partir da determinação do volume globular, contagem de eritrócitos e dosagem de hemoglobina total foram determinados os índices hematimétricos, utilizando-se as formulações estabelecidas por Wintrobe (1934).

Na contagem de leucócitos foi utilizada a metodologia proposta por Berra et al. (1993), em que a contagem dos leucócitos totais foi realizada de forma direta em câmara de Neubauer. Para a con- 
tagem diferencial (neutrófilos, linfócitos, monócitos, eosinófilos) foram confeccionados esfregaços sanguíneos sem o uso de anticoagulantes, que posteriormente foram corados pancromaticamente pelo método de Rosenfeld (1947), e contados 100 células em cada extensão sanguínea, e foi estabelecido o percentual de cada componente celular. No mesmo esfregaço sanguíneo usado na diferencial de leucócitos, foi quantificado o número de trombócitos (por $\mu \mathrm{L}$ ) utilizando-se da seguinte fórmula:

Trombócitos $=\underline{\mathrm{n} \times}$ trombócitos na extensão $\times \mathrm{n}$ o de eritrócitos (por $\mu \mathrm{L})$ 2000 eritrócitos contados na extensão sanguínea

Para a determinação quantitativa dos parâmetros bioquímicos foram utilizadas as frações de soro obtidas por centrifugação das amostras sem o uso de anticoagulante. As atividades enzimáticas foram determinadas na temperatura de $37^{\circ} \mathrm{C}$, com a utilização de reagentes comerciais padronizados.

A concentração de glicose plasmática foi realizada por método enzimático (Tavares-Dias \& Sandrim 1999), utilizando-se o reagente comercial Glicose PAP Liquiform cat. 84 da Labtest Diagnóstica ${ }^{\circledR}$, Lagoa Santa, MG. 0 nível sérico do colesterol foi determinado pelo método enzimático colorimétrico, em uma reação catalisada pela colesterol oxidase, com a utilização do reagente comercial Colesterol Liquiform cat. 76 da Labtest Diagnóstica ${ }^{\circledR}$,
Lagoa Santa, MG, que permitiu quantificar a concentração de colesterol por meio da metodologia enzimática (Bergmeyer 1984). A concentração de triglicérides foi realizada por método enzimático colorimétrico, em uma reação catalisada pela glicerolfosfato oxidase (Trinder 1969), empregando-se o reagente comercial Triglicérides Liquiform cat. 87 da Labtest Diagnóstica ${ }^{\circledR}$, Lagoa Santa, MG. Para a determinação de proteína total utilizou-se o método do biureto modificado (Henry et al. 1974), utilizando-se o reagente comercial Proteína Total cat. 99 da Labtest Diagnóstica ${ }^{\circledR}$, Lagoa Santa, MG.

A concentração dos íons séricos foi determinada em fotômetro de chama (Zeiss M4Q2) para a emissão de sódio e potássio, enquanto que os íons cloreto e cálcio foram quantificados por metodologia colorimétrica empregando-se os reagentes comerciais Cloretos cat. 49 e Cálcio Liquiform cat. 90 da Labtest Diagnóstica ${ }^{\circledR}$, Lagoa Santa, MG.

Os resultados das variáveis hematológicas e bioquímicas avaliadas foram submetidos à análise de variância pelo pacote computacional SAS Institute (2002). Para as variáveis quantitativas que apresentaram homogeneidade e distribuição normal (hemácias, volume globular, hemoglobina, índices hemantimétricos, leucócitos, percentual de distribuição celular (neutrófilos, linfócitos e trombócitos), proteína total, colesterol, glicose e os íons séricos) foram aplicadas ANOVA e teste de SNK (Student-Newman-Keuls)

Quadro 1. Valores médios das características hematológicas de Oreochromis niloticus sob estresse por exposição ao ar. Goiânia, 2010

\begin{tabular}{lccccccc}
\hline \multirow{2}{*}{ Tratamentos } & \multicolumn{7}{c}{ Características } \\
\cline { 2 - 7 } & $\begin{array}{c}\mathrm{RBC}^{* *} \\
\left(10^{6} / \mathrm{mL}\right)\end{array}$ & $\begin{array}{c}\mathrm{VG}^{* *} \\
(\%)\end{array}$ & $\begin{array}{c}\mathrm{Hb}^{* *} \\
(\mathrm{~g} / \mathrm{dL})\end{array}$ & $\begin{array}{c}\mathrm{VCM}^{* *} \\
(\%)\end{array}$ & $\begin{array}{c}\mathrm{HCM}^{* *} \\
(\mathrm{pg})\end{array}$ & $\begin{array}{c}\text { CHCM }^{* *} \\
(\%)\end{array}$ & $\begin{array}{c}\text { Leucócitos* } \\
(\mathrm{mL})\end{array}$ \\
\hline Controle & 1,757 & 29,75 & 7,97 & 169,0 & 45,7 & 26,9 & $13854,62 \mathrm{~b}$ \\
E30' & 1,480 & 29,62 & 8,12 & 204,8 & 57,9 & 27,9 & $11928,50 \mathrm{ab}$ \\
E60' & 1,490 & 29,87 & 8,66 & 203,2 & 58,9 & 29,0 & $9784,00 \mathrm{ab}$ \\
E90' & 1,552 & 29,25 & 8,20 & 189,7 & 53,6 & 28,5 & $7084,50 \mathrm{a}$ \\
E60'R30' & 1,494 & 28,75 & 7,60 & 193,2 & 51,5 & 26,8 & $9377,87 \mathrm{ab}$ \\
E60'R90' & 1,524 & 29,00 & 8,23 & 193,2 & 54,9 & 28,5 & $11979,00 \mathrm{ab}$ \\
E90'R30' & 1,585 & 28,62 & 7,88 & 182,0 & 50,0 & 27,7 & $6710,12 \mathrm{a}$ \\
E90'R90' & 1,536 & 29,57 & 8,94 & 193,2 & 58,5 & 30,9 & $10749,00 \mathrm{ab}$ \\
Média & 1,552 & 29,30 & 8,203 & 191,2 & 53,9 & 28,3 & 10183,45 \\
Coef. Variação,\% & 11,84 & 9,77 & 11,80 & 13,31 & 19,62 & 16,31 & 35,67 \\
Erro-padrão & 0,065 & 1,012 & 0,342 & 8,999 & 3,741 & 1,631 & 1284,383 \\
Probabilidade & 0,083 & 0,979 & 0,165 & 0,169 & 0,171 & 0,722 & 0,002
\end{tabular}

* Médias seguidas de mesmas letras minúscula, na coluna, não diferem estatisticamente pelo teste SNK, 5\% de significância. ${ }^{* *}(\mathrm{P}>0,05)$.

Quadro 2. Distribuição percentual das células de defesa orgânica em Oreochromis niloticus sob estresse por exposição ao ar, com valores de média, desvio-padrão e coeficiente de variação. Goiânia, 2010

\begin{tabular}{|c|c|c|c|c|c|}
\hline \multirow[t]{2}{*}{ Tratamentos } & \multicolumn{5}{|c|}{ Características } \\
\hline & Neutrófilo $(\%)$ & Linfócito a (\%) & Monócito ${ }^{\mathrm{b}, \mathrm{c}}(\%)$ & Eosinófilo $^{\mathrm{b}, \mathrm{c}}(\%)$ & Trombócito ${ }^{\mathrm{b}}(\%)$ \\
\hline Controle & $13,3 \pm 4,9 b$ & $37,8 \pm 10,4 a$ & $4,9 \pm 3,9$ & $0,25 \pm 0,5$ & $43,9 \pm 12,9$ \\
\hline E30' & $14,3 \pm 6,1 b$ & $34,0 \pm 7,7 a b$ & $5,3 \pm 2,9$ & $0,5 \pm 0,8$ & $46,0 \pm 9,8$ \\
\hline E60' & $22,1 \pm 6,7 a b$ & $29,1 \pm 11,3 a b$ & $4,6 \pm 2,6$ & $0,8 \pm 0,9$ & $43,4 \pm 7,9$ \\
\hline E90' & $23,0 \pm 8,7 a b$ & $26,4 \pm 9,3 a b$ & $5,1 \pm 2,7$ & $0,8 \pm 1,2$ & $44,8 \pm 7,5$ \\
\hline E60'R30' & $20,6 \pm 6,3 a b$ & $29,5 \pm 7,4 a b$ & $4,6 \pm 2,0$ & $0,5 \pm 0,8$ & $44,8 \pm 6,2$ \\
\hline E60’R90' & $24,8 \pm 6,8 a$ & $26,8 \pm 9,4 a b$ & $5,1 \pm 1,7$ & $0,8 \pm 0,7$ & $42,6 \pm 7,5$ \\
\hline E90’R30' & $26,8 \pm 7,3 a$ & $21,1 \pm 8,8 \mathrm{ab}$ & $5,1 \pm 2,7$ & $0,8 \pm 0,9$ & $46,3 \pm 7,5$ \\
\hline E90’R90' & $25,1 \pm 9,6 a$ & $26,0 \pm 11,4 b$ & $5,1 \pm 2,4$ & $0,6 \pm 0,8$ & $43,1 \pm 7,2$ \\
\hline Média & 21,4 & 28,7 & 5,00 & 0,6 & 44,3 \\
\hline Coef. Variação, \% & 33,69 & 33,26 & 50,59 & 137,82 & 19,26 \\
\hline Erro-padrão & 2,544 & 3,379 & 0,894 & 0,289 & 3,017 \\
\hline Probabilidade & 0,001 & 0,034 & 0,998 & 0,809 & 0,983 \\
\hline
\end{tabular}

a Médias seguidas de mesmas letras minúscula, na coluna, não diferem estatisticamente pelo teste SNK, 5\% de significância; ${ }^{\mathrm{b}}(\mathrm{P}>0,05)$;

c Variáveis submetidas ao teste de Kruskal-Wallis $(\mathrm{P}<0,05)$, por apresentarem Coef. de Variação >50\%. 
para se realizar a comparação entre os grupos $(\mathrm{P}<0,05)$. Para as variáveis quantitativas que não apresentaram distribuição normal (percentual de distribuição celular - monócitos e eosinófilos, triglicérides) foi utilizado o teste não paramétrico de Kruskal-Wallis $(\mathrm{P}<0,05)$.

\section{RESULTADOS}

Todos os peixes utilizados encontravam-se sem lesões externas e aparentemente isentos de ectoparasitas. Durante o período de cultivo dos animais para as análises, a temperatura variou de 24,3 a $27,6^{\circ} \mathrm{C}$, o oxigênio dissolvido na água oscilou de 5,18 a 5,70mg/L e a taxa de saturação de oxigênio entre 66,1 e 71,8\%. Os valores médios dos parâmetros hematológicos (hemácias - RBC, volume globular - VG, hemoglobina - Hb, volume corpuscular médio - VCM, hemoglobina corpuscular média - HCM, concentração de hemoglobina corpuscular média - CHCM e leucócitos totais) de tilápia-do-Nilo (Oreochromis niloticus) antes e após a submissão de estresse por exposição ao ar estão apresentados nos Quadros 1 e 2 .

Os tratamentos empregados não influenciaram ( $\mathrm{P}>0,05)$ a contagem total de hemácias, o percentual de volume glo-

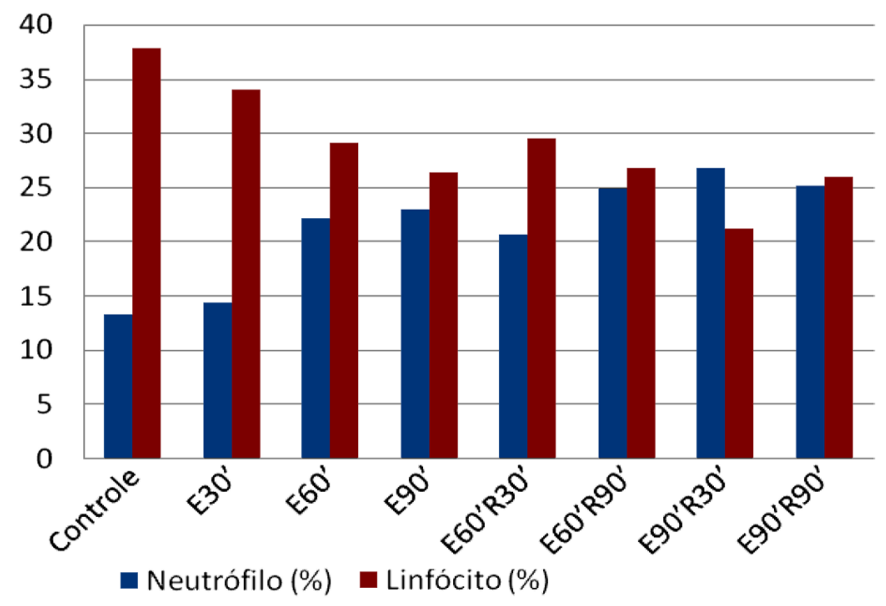

Fig.1. Distribuição percentual de neutrófilos e linfócitos em exemplares de Oreochromis niloticus sob estresse por exposição ao ar

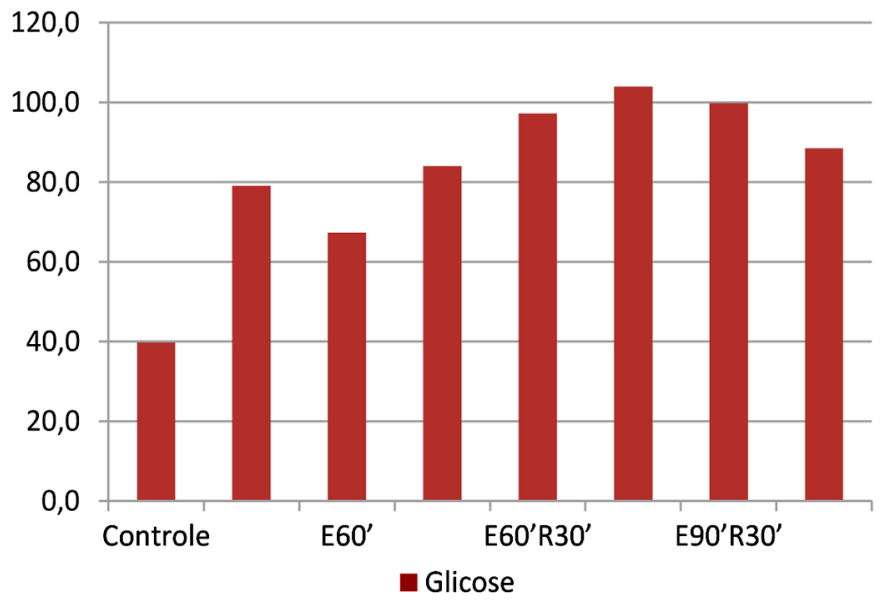

Fig.2.Valores médios de glicose plasmática em tilápias-do-Nilo (Oreochromis niloticus) sob estresse por exposição ao ar bular, o teor de hemoglobina e os índices hemantimétricos (VGM, HCM e CHCM). A contagem total das células leucocitárias apresentou valores progressivamente menores de acordo com o aumento do período de exposição (estresse mais intenso), sendo observada uma predominância linfocitária (Fig.1).

Neste experimento, a glicemia foi afetada $(\mathrm{P}<0,05)$, pelos diferentes tratamentos avaliados, o controle apresentou menor valor glicêmico que os demais tratamentos empregados (Fig.2). Os tratamentos E30', E60' e E90' demonstraram resultados similares entre si, com resposta intermediária para essa variável, enquanto o tratamento E60'R90' apresentou maior glicemia, embora seu resultado seja análogo aos demonstrados pelos tratamentos E90'R30' e E90'R90'. Em contraste, na exposição ao ar dos exemplares após 30, 60 e 90 minutos, assim como o intervalo de recuperação de 30 minutos após exposição por 60 minutos, pode-se caracterizar a elevação nos níveis de glicose como consequência de uma situação de estresse.

Quadro 3. Variáveis bioquímicas de Oreochromis niloticus sob estresse por exposição ao ar, com valores de média e coeficiente de variação. Goiânia, 2010

\begin{tabular}{|c|c|c|c|c|}
\hline \multirow[t]{2}{*}{ Tratamentos } & \multicolumn{4}{|c|}{ Características } \\
\hline & $\begin{array}{l}\text { Prot. total }^{\mathrm{b}} \\
\text { (g/dL) }\end{array}$ & $\begin{array}{c}\text { Colesterol }^{a} \\
\text { (mg/dL) }\end{array}$ & $\begin{array}{l}\text { Triglicérideos }{ }^{\mathrm{b}, \mathrm{c}} \\
\text { (g/dL) }\end{array}$ & $\begin{array}{l}\text { Glicose }^{a} \\
\text { (mg/dL) }\end{array}$ \\
\hline Controle & 2,83 & $99,62 \mathrm{ab}$ & 216,91 & $39,75 d$ \\
\hline E30' & 2,97 & $100,50 \mathrm{ab}$ & 251,01 & $79,00 \mathrm{ac}$ \\
\hline E60' & 2,92 & $101,37 \mathrm{ab}$ & 215,63 & $67,25 c$ \\
\hline E90' & 2,83 & $115,57 a$ & 174,86 & $84,00 \mathrm{abc}$ \\
\hline E60'R30' & 2,91 & $106,62 a$ & 251,63 & $97,12 \mathrm{ab}$ \\
\hline E60'R90' & 2,80 & $76,75 b$ & 168,22 & $103,87 b$ \\
\hline E90'R30' & 2,97 & $94,25 a b$ & 141,62 & $99,75 a b$ \\
\hline E90'R90' & 3,11 & $98,86 a b$ & 140,82 & $88,42 a b$ \\
\hline Média & 2,92 & 99,19 & 195,09 & 82,39 \\
\hline Coef. Variação, \% & 10,02 & 17,30 & 55,61 & 18,84 \\
\hline Erro-padrão & 0,103 & 6,068 & 38,354 & 5,487 \\
\hline Probabilidade & 0,477 & 0,004 & 0,234 & 0,001 \\
\hline
\end{tabular}

${ }^{a}$ Médias seguidas de mesmas letras minúscula, na coluna, não diferem estatisticamente pelo teste SNK, 5\% de significância;

${ }^{\mathrm{b}}(\mathrm{P}>0,05)$; ${ }^{\mathrm{C}}$ Variáveis submetidas ao teste de Kruskal-Wallis $(\mathrm{P}<0,05)$, por apresentarem Coef. de Variação acima de 50\%.

Quadro 4. Variáveis eletrolíticas de Oreochromis niloticus sob estresse por exposição ao ar, com valores de média e coeficiente de variação. Goiânia, 2010

\begin{tabular}{|c|c|c|c|c|}
\hline \multirow[t]{2}{*}{ Tratamentos } & \multicolumn{4}{|c|}{ Características } \\
\hline & $\begin{array}{c}\text { Cálcio }^{\mathrm{a}} \\
(\mathrm{mg} / \mathrm{dL})\end{array}$ & $\begin{array}{l}\text { Cloreto }^{\mathrm{b}} \\
(\mathrm{mEq} / \mathrm{L})\end{array}$ & $\begin{array}{l}\text { Sódio }^{a} \\
\text { (g/dL) }\end{array}$ & $\begin{array}{l}\text { Potássio }^{\mathrm{b}} \\
\text { (mg/dL) }\end{array}$ \\
\hline Controle & $12,53 a b$ & 138,75 & $137,50 \mathrm{ab}$ & 3,12 \\
\hline E30' & $13,10 \mathrm{ab}$ & 136,87 & $137,12 \mathrm{ab}$ & 3,26 \\
\hline E60' & $12,82 \mathrm{ab}$ & 137,75 & $135,25 b$ & 3,02 \\
\hline E90' & $13,22 \mathrm{a}$ & 136,86 & $142,50 \mathrm{ab}$ & 3,12 \\
\hline E60'R30' & $12,12 \mathrm{ab}$ & 137,00 & $139,00 \mathrm{ab}$ & 3,00 \\
\hline E60'R90' & $12,28 \mathrm{ab}$ & 133,87 & $137,12 \mathrm{ab}$ & 3,00 \\
\hline E90'R30' & $12,33 \mathrm{ab}$ & 132,12 & $146,37 a$ & 3,08 \\
\hline E90'R90' & $11,73 b$ & 134,00 & $144,37 \mathrm{ab}$ & 3,02 \\
\hline Média & 12,52 & 135,90 & 139,90 & 3,08 \\
\hline Coef. Variação, \% & 7,53 & 3,45 & 4,82 & 19,07 \\
\hline Erro-padrão & 0,333 & 1,659 & 2,386 & 0,207 \\
\hline Probabilidade & 0,039 & 0,087 & 0,013 & 0,987 \\
\hline
\end{tabular}

$\overline{{ }^{a}}$ Médias seguidas de mesmas letras minúscula, na coluna, não diferem estatisticamente pelo teste SNK, $5 \%$ de significância; ${ }^{\mathrm{b}}(\mathrm{P}>0,05)$. 
A proteína total e os triglicerídeos não foram afetados $(\mathrm{P}>0,05)$ pelos diferentes tratamentos aos quais foram submetidos os animais (Quadro 3). 0 colesterol sérico foi menor no tratamento E60'R90' em relação aos tratamentos E90' e E60'R30', sendo que os demais tratamentos não se diferenciaram entre si. Observou-se que houve diferenças significativas $(\mathrm{P}>0,05)$ nos resultados de cálcio e sódio (Quadro 4), em virtude dos diferentes tratamentos empregados. 0 menor valor de cálcio foi obtido no E90'R90', sendo divergente do E90' e similar aos demais tratamentos empregados na condução do ensaio. 0 sódio por sua vez foi maior no E90'R30' quando comparado ao tratamento E60' que apresentou o menor índice para esse eletrólito, entretanto o resultado obtido foi semelhante aos evidenciados nos demais tratamentos.

\section{DISCUSSÃO}

De acordo com Ranzani-Paiva (1991), as oscilações dos valores hematológicos em peixes são influenciadas pela temperatura, oxigênio dissolvido, salinidade e $\mathrm{pH}$, assim como por estresse, ciclo sazonal e fatores endógenos como o sexo, estádio de maturação gonadal, estado nutricional e doenças. 0 autor enfatiza que essa variação ocorre não só entre espécies, mas também entre indivíduos da mesma espécie, de acordo com as condições fisiológicas dos animais.

Neste estudo, comparando-se com dados obtidos em tilápias-do-Nilo no Brasil, o número de eritrócitos encontrado foi semelhante ao observado por Barros et al. (2002), Martins et al. (2004) e Ghiraldelli et al. (2006). Entretanto, estes resultados foram divergentes ao encontrados por Azevedo et al. (2006), que encontraram valores menores dessa variável ao se trabalhar com exemplares mantidos em piscicultura consorciada com suínos. Tavares-Dias \& Moraes (2003) avaliaram exemplares machos de $O$. niloticus e 0 . rendalli Boulenger, 1896 mantidos em pesque-pague e encontraram resultados similares ao observado nessa pesquisa.

A média geral por tratamento do percentual de volume globular mostrou uniformidade e dentro da normalidade, sendo similar aos dados obtidos por Tavares-Dias \& Faustino (1998), Yildiz \& Pulatsü (1999), Tavares-Dias et al. (2000a,b), Tavares-Dias \& Moraes (2003), Benli \& Yildis (2004), Azevedo et al. (2006), mas menores do que o verificado em condições de laboratório por Martins et al. (2004). Esse parâmetro pode, em parte, revelar o nível de estresse a que os peixes estão submetidos, embora na presença de diferentes agentes estressantes tais como peixes expostos a estímulos únicos e consecutivos de estresse, possa variar (Martins et al. 2002).

0 teor de hemoglobina encontrado no ensaio foi análogo aos observados por Tavares- Dias \& Faustino (1998), Ueda et al. (1997) Tavares-Dias et al. (2000a). Porém, foi maior do que o encontrado por Silveira \& Rigores (1989) ao trabalhar em O. aureus, e por Wepener et al. (1992) ao avaliar Tilapia sparrmanii. Todavia, tais discrepâncias entre tilápias do mesmo gênero provavelmente se devem a escolha do anticoagulante utilizado na colheita das amostras, em que amostras oriundas de plasma heparinizado são maiores quando comparados às amostras obtidas com a utilização de EDTA (Tavares-Dias \& Sandrim 1998).

Neste trabalho, o número total de trombócitos foi obtido a partir das extensões sanguíneas e não em hemocitômetro. Tal procedimento tornou o resultado mais seguro, pois o núcleo da hemácia de peixes poderia ser confundido com trombócito, se o exame fosse feito por meio de hemocitômetro. Em peixes, além de sua influência na coagulação do sangue, pouco se conhece sobre as funções dos trombócitos, por serem células ainda pouco estudadas, mas acredita-se que possam estar relacionadas com o sistema de defesa (presente em exsudatos inflamatórios e atividade fagocitária), como relatado por Matushima \& Mariano (1996). Por este motivo, optou-se por sua contagem e distribuição juntamente com os leucócitos, denominando-se esse conjunto de células sanguíneas de defesa orgânica (Matushima \& Mariano 1996, Azevedo et al. 2006). Os trombócitos foram contados juntamente com os diversos tipos de leucócitos, todavia, eles não foram considerados como célula de linhagem leucocitária (Matushima \& Mariano 1996).

Verificou-se neste ensaio, a ocorrência de diferença significativa somente para a variável leucocitária, em que o E90' foi divergente do controle quanto à exposição, sendo similar aos demais tratamentos. Isso demonstra que, a quantidade de leucócitos circulantes foi inversamente proporcional ao intervalo de exposição dos animais ao estresse por exposição ao ar. Esses resultados corroboram os descritos por Falcon et al. (2008), que demonstraram que o estresse pelo frio pode levar a uma queda da resistência imunológica dos peixes, o que contribui para quadros de infecção patogênica.

Essa redução no número total de células brancas pode ser ainda justificada pela variação das células analisadas, sendo que os linfócitos, os quais estão relacionados à produção de anticorpos e resposta celular humoral, representam a quase totalidade dos leucócitos. Resultados análogos foram reportados por Barton \& Iwama (1991) ao constatarem a queda do número de células brancas totais e de linfócitos, pós-estresse.

Observou-se que houve predominância de linfócitos seguidos de neutrófilos e monócitos na contagem diferencial de leucócitos, semelhante ao observado por Ezzat et al. (1974), Lea Master et al. (1990), Tavares-Dias \& Faustino (1998), Tavares-Dias et al. (2000b), Tavares-Dias \& Moraes (2004) e Azevedo et al. (2006). Outros autores, Ueda et al. (1997) e Tavares-Dias et al. (2000a), verificaram predominância de neutrófilos na contagem diferencial. A predominância de linfócitos no sangue de peixes não está bem esclarecida. Nos tecidos, as células mononucleares (linfócitos e macrófagos) prevalecem na reação de defesa do organismo, porém, em situações de estresse, o número de linfócitos circulantes diminui. Dessa forma, os linfócitos em peixes podem estar presentes no processo inflamatório, na resposta humoral e também mediada por células frente a diversas situações (Iwama \& Nakanishi 1996).

Pickering (1981) relatou que a queda de linfócitos pode estar relacionada com redução da capacidade do peixe de se defender contra agentes patógenos. Trata-se do resul- 
tado que reafirma a hipótese anteriormente apresentada por Barton \& Iwama (1991) e demonstra a severidade do estresse, o qual poderia, por período prolongado, vencer o sistema de defesa do organismo. Pois, juntamente com a perda das funções fagocitárias das células de defesa orgânica, o número total de leucócitos circulantes foi também reduzido em peixes estressados.

Os neutrófilos são componentes do sistema imunológico que formam a primeira linha de defesa celular contra agentes invasores e têm como função a fagocitose. Sob estresse agudo um aumento da resposta imune inata tem sido descrita, enquanto os efeitos deletérios têm sido observados como consequência de estresse crônico (Vazzana et al. 2002). Os monócitos são células com função fagocitária e de eliminação de bactérias. São precursores de macrófagos e consideradas células essenciais à vida (Feldman et al. 2000). A função normal dos linfócitos dos peixes é dependente da adaptação da membrana lipoprotéica; portanto, a composição dos ácidos graxos e a temperatura ambiente estão descritas como fatores que determinam a fluidez e permeabilidade das membranas (Tavares-Dias \& Moraes 2004).

Nos tratamentos estabelecidos como períodos de recuperação (E60'R30', E60'R90', E90'R30' e E90'R90') frente ao estresse ao qual foram submetidos os animais, verificou-se que os intervalos de tempo empregados não foram satisfatórios para verificar o retorno dos valores médios das células de defesa aos valores basais (controle). Comportamento semelhante foi observado no peixe onívoro híbrido tambacu (Piaractus mesopotamicus macho x Colossoma macropomum fêmea) por Martins et al. (2002), ao avaliarem estresse simples e consecutivo. Isso sugere que os animais avaliados no presente estudo iriam precisar de mais tempo para retornar aos valores basais, uma vez que, o maior intervalo de tempo empregado no ensaio foi insuficiente para o retorno da contagem de linfócitos e neutrófilos aos valores médios obtidos com os exemplares do grupo controle.

A glicose plasmática é bom indicador de estresse, pois as alterações são facilmente detectáveis e sua avaliação pode ser realizada com medidores de glicose de simples utilização (Gomes et al. 2005, Simões \& Gomes 2009), para diagnosticar a ocorrência de estresse fisiológico (Wedemeyer et al. 1990).

Este resultado evidencia que a exposição ao ar é estressante aos peixes, e que tais dados corroboram aos encontrados por Martins et al. (2004), Silva et al. (2009), Simões \& Gomes (2009). Contraditoriamente, Deriggi et al. (2006) verificaram valores médios menores para esta variável quando trabalharam com respostas metabólicas de 0 . niloticus submetidas ao manuseio e ao anestésico eugenol.

Verificou-se que a concentração sérica de colesterol foi menor no momento E60'R90' quando comparado aos demais períodos. Isso demonstra que o colesterol foi consumido para obtenção de pregnenolona, que é precursora na síntese de cortisol, que por sua vez, estaria atuando sobre a fisiologia do animal promovendo alterações metabólicas (Oba et al. 2009).

Araujo et al. (2004) verificaram valores inferiores de cálcio aos obtidos neste ensaio, ao se utilizar exemplares onívoros de tambaqui (Colossoma macropomun) submetidos a banhos terapêuticos de formalina. 0 equilíbrio nos níveis de cálcio deve ser mantido para o perfeito funcionamento das funções neuromusculares e manutenção da homeostase orgânica (Shiau \& Hwang 1993, Björnsson et al. 1999).

Durante o estresse, o peixe apresenta aumento no fluxo sanguíneo e na permeabilidade das brânquias, principalmente por ação de catecolaminas e cortisol, o que facilita o transporte de oxigênio para atender a demanda biológica dos tecidos. Entretanto, a mudança da permeabilidade branquial leva à perda de eletrólitos sanguíneos e distúrbios osmorregulatórios nos peixes de água doce (McDonald \& Milligan 1997).

Nesse ensaio, os íons cloretos e potássio não se alteraram após os estímulos estressantes. Os resultados obtidos foram similares aos demonstrados por Chagas et al. (2003), ao analisarem eletrólitos de tambaquis (Colossoma macropomun) oriundos de cultivos em tanque-rede. Esses autores verificaram que não houve diferença significativa para os íons séricos cloretos, e potássio plasmático de exemplares no período anterior à exposição, bem como nos tempos de exposição de 30, 60 e 120 minutos e após 24 horas de recuperação.

Assim, estas informações e conhecimentos sobre as variáveis hematológicas e bioquímicas da tilápia-do-Nilo submetidas ao estresse por exposição ao ar podem ser utilizadas pelo piscicultor como ferramenta de avaliação do seu sistema de criação.

Agradecimentos.- Ao Setor de Piscicultura da EVZ/UFG, em especial ao Prof. Paulo César Silva pela concessão dos animais e a infraestrutura para a realização deste trabalho. Aos alunos e bolsistas do Setor que auxiliaram na condução do experimento. Agradecemos também ao Conselho Nacional de Desenvolvimento Científico e Tecnológico (CNPq) pela bolsa concedida e a Escola de Veterinária e Zootecnia da UFG.

\section{REFERÊNCIAS}

Araújo L.D., Chagas E.C., Gomes L.C. \& Brandão \& F.R. 2004. Efeito de banhos terapêuticos com formalina sobre indicadores de estresse em tambaqui. Pesq. Agropec. Bras. 39:217-221.

Azevedo T.M.P., Martins M.L., Yamashita M.M. \& Francisco C.J. 2006. Hematologia de Oreochromis niloticus: comparação entre peixes mantidos em piscicultura consorciada com suínos e pesque-pague no vale do rio Tijucas, Santa Catarina, Brasil. Bolm Inst. Pesca 32:41-49.

Barros M.M., Pezzato L.E., Kleemann G.K., Hisano H. \& Rosa G.J.M. 2002. Níveis de vitamina $\mathrm{C}$ e ferro para tilápia do Nilo (Oreochromis niloticus). Revta Bras. Zootec. 31:2149-2156.

Barton B.A. \& Iwama G.K. 1991. Physiological changes in fish from stress in aquaculture with emplasis on the response and effects of corticosteroids. Annu. Rev. Fish Dis. 1:3-26.

Benli A.C.K. \& Yildis H.Y. 2004. Blood parameters in Nile tilapia (Oreochromis niloticus L.) spontaneously infected with Edwardsiella tarda. Aquac. Res. 35:1388-1390.

Bergmeyer H.U. 1984. Methods of enzimatic analysis, $3^{\text {th }}$ ed. Verlang Chemie Publishers, Weinhein. 8:141-148.

Berra J.A.P., Fiocco R.A., Ramos R.O. \& Ramos S.M. 1993. Técnicas para contagem global de globules brancos em peixes. Bolm Téc. CEPTA 6:63-66.

Björnsson B.T., Persson P., Larsson D., Johannsson S.H. \& Sundell K. 1999. Calcium balance in teleost fish and endocrine control mechanisms, p.110. In: Danks J., Dacke C., Flik G. \& Gay C. (Eds), Calcium Metabolism. BioScientifica, Bristol. 
Brasil 2010. Boletim Estatístico de Pesca e Aquicultura. Ministério da Pesca e Aquicultura, Brasília. 99p.

Carvalho C.S. \& Fernandes M.N. 2006. Effect of temperature on copper toxicity and hematological responses in the neotropical fish Prochilodus scrofa at low and high pH. Aquacult. 251:109-117.

Chagas E.C., Lourenço J.N.P., Gomes L.C. \& Val A.L. 2003. Desempenho e estado de saúde de tambaquis cultivados em tanques-rede sob diferentes densidades de estocagem. Anais $12^{\circ}$ Simpósio Brasileiro de Aquicultura, Goiânia, GO, p.83-93.

Collier H.B. 1944. The standardization of blood haemoglobin determinations. Can. Med. Assoc. J. 50:550-552.

Costa O.F.T., Ferreira D.J.S., Mendonça F.L.P. \& Fernandes M.N. 2004. Susceptibility of the amazonian fish, Colossoma macrospomun (Serrasalminae) to short-term exposure to nitrite. Aquacult. 232:627-636.

Deriggi G.F., Inoue L.A.K.A. \& Moraes G. 2006. Stress responses to handling in Nile tilapia (Oreochromis niloticus Linnaeus): assessment of eugenol as an alternative anesthetic Acta Sci., Biol. Sci. 28:269-274.

Ezzat A.A., Shabana M.B. \& Farghaly A.M. 1974. Studies on the blood characteristics of Tilapia zilli (Gervais) I. Blood cells. J. Fish Biol. 6:1-12.

Falcon D.R., Barros M.M., Pezzato L.E., Solarte W.V.N. \& Guimarães I. 2008. Leucograma da tilápia-do-Nilo arraçoada com dietas suplementadas com níveis de vitamina C e lipídeo submetidas a estresse por baixa temperatura. Ciênc. Anim. Bras. 9:543-551.

Feldman B.F., Zinkl J.G. \& Jain N.C. 2000. Schalm's Veterinaty Hematology. $5^{\text {th }}$ ed. Lippincott Williams and Wilkins, Philadelphia. 1344p.

Goldenfarb P.B., Bowyer F.P., Hall E. \& Brosious E. 1971. Reproducibility in the hematology laboratory: the microhematocrit determination. Am. J. Clin. Pathol. 56:35-39.

Gomes L.C., Chagas E.C., Crescêncio R., Pessoa M.A., Silva A.L.F., Carvalho E.S., Andrade Junior G., Brito M.V.T. \& Porto M.S.A. 2005. Validation of a simple portable instrument for measurement of blood glucose in four amazon fishes. J. Aquac. Trop. 20:101-109.

Ghiraldelli L., Martins M.L., Yamashita M.M. \& Jerônimo G.T. 2006. Haematology of Oreochromis niloticus (Cichlidae) and Cyprinus carpio (Cyprinidae) maintained in different conditions of handling and feeding from the State of Santa Catarina, Brazil. Acta Sci., Biol. Sci. 28:319-325.

Henry R.J., Cannon D.C. \& Winkelman J.W. 1974. Clinical Chemestry: Principles and technics. $2^{\text {nd }}$ ed. Harper and Row, New York, p.405-435.

Iwama G.K. 1993. Intensive fish productions, Guided Independent Study: Course manual. UBC Access, University of British Columbia, Vancouver. $130 \mathrm{p}$.

Iwama G. \& Nakanishi T. 1996. The Fish Immune System. Academic Press, London. 380p.

Lea Master B.R., Brock J.A., Fujioka R.S. \& Nakamura R.M. 1990. Hematologic and blood chemistry values for Sarotherodon melanotheron and a red hybrid tilapia in freshwater and seawater. Comp. Biochem. Physiol. 97:525-529.

Martins M.L., Moraes F.R., Fujimoto R.Y., Nomura D.T. \& Fenerick Jr J. 2002. Respostas do híbrido tambacu (Piaractus mesopotamicus Holmberg, 1887 macho x Colossoma macropomum Cuvier, 1818 fêmea) a estímulos simples e consecutivos de captura. Bolm Inst. Pesca 28:195-204.

Martins M.L., Pilarsky F., Onaka E.M., Nomura D.T., Fenerick Jr J., Ribeiro K., Yiazaki D.M.Y., Castro M.P. \& Malheiros E.B. 2004. Hematologia e resposta inflamatória aguda em Oreochromis niloticus (Osteichthyes: Cichlidae) submetida aos estímulos único e consecutivo de estresse de captura. Bolm Inst. Pesca 30:71-80.

Matushima E.R. \& Mariano M. 1996. Kinetics of the inflammatory reaction induced by carrageenin in the swimbladder of Oreochromis niloticus (Nile tilapia). Braz. J. Vet. Res. Anim. Sci. 33:5-10.

Mazeaud M.M., Mazeaud F. \& Donaldson E.M. 1977. Primary and secondary effects of stress in fish: Some new data with a general review. T. Am. Fish. Soc. 106:201-212.

McDonald G. \& Milligan L. 1997. Ionic, osmotic and acid-base regulation in stress, p.119-144. In: Iwana G.K., Pickering A.D., Sumpter J.P. \& Schreck C.B. (Eds), Fish Stress and Health in Aquaculture. Cambridge University Press, New York.
Moraes G., Polez V.L.P. \& Iwama G.K. 2004. Biochemical responses of two erythrinidae fish to environmental ammonia. Braz. J. Biol. 64:95-102.

Oba E.T., Mariano W.S. \& Santos L.R.B. 2009. Estresse em peixes cultivados: agravantes e atenuantes para o manejo rentável, p.226-247. In: Tavares-Dias M. (Ed.), Manejo e Sanidade de Peixes em Cultivo. Embrapa Amapá, Macapá.

Oliveira-Junior A.A., Tavares-Dias M. \& Marcon J.L. 2008. Biochemical and hematological reference ranges for Amazon freshwater turtle, Podocnemis expansa (Reptilia: Pelomedusidae), with morphologic assessment of blood cells. Res. Vet. Sci. 86:146-151.

Pickering A.D. 1981. Stress and Fish. Academic Press, London.

Ranzani-Paiva M.J.T. 1991. Hematologia de peixes, p.65-70. In: Santos H.S.L. (Ed), Histologia de Peixes. Faculdade de Ciências Agrárias e Veterinárias, Unesp, São Paulo.

Rijnberk A. \& Mol J.A. 1997. Adrenocortical function, p.533-568. In: Kaneko J.J., Harvey J.W. \& Bruss M.L. (Eds), Clinical Biochemistry of Domestic Animal. $5^{\text {th }}$ ed. Academic Press, San Diego.

Rosenfeld G. 1947. Corânte pancrômico para hematologia e citologia clínica: nova combinação dos componentes do May-Grünwald e do Giemsa num só corante de emprego rápido. Memo. Inst. Butantan 20:329-334.

SAS Institute 2002. SAS User's Guide: Statistics, Cary. 846p.

Scorvo-Filho J.D. 2003. Panor. Aquic. Nacional. In: Informes Técnicos - Associação Catarinense de Aquicultura. Disponível em <http://www.acaq. org.br/arquivos/Panorama_aquicultura_nacional.pdf> Acesso em $3 \mathrm{dez}$. 2011.

Shiau S.Y. \& Hwang J.Y. 1993. Vitamin D requirements of juvenile hybrid tilapia Oreochromis niloticus x Oreochromis aureus. Bull. Jpn. Soc. Sci. Fish. 59:553-558.

Silva R.D., Rocha L.O., Fortes B.D.A., Rodrigues C.P.F., Lobo J.R., Faleiro M.B.R., De Paula F.G. \& Vieira D. 2009. Determinação de glicose plasmática em exemplares adultos de Tilápia (Oreochromis niloticus) por glicosímetro digital portátil e por método enzimático. Anais 6 o Congresso de Ensino Pesquisa e Extensão, Goiânia, GO, p.5914-5919.

Silveira R. \& Rigores C. 1989. Características hematológicas normales de Oreochromis niloticus em cultivo. Revia Latinoam. Acuicult. 39:54-56.

Simões L.N. \& Gomes L.C. 2009. Eficácia do mentol como anestésico para juvenis de tilápia-do-Nilo (Oreochromis niloticus). Arq. Bras. Med. Vet. Zootec. 61:613-620.

Souza M.L.R. \& Maranhão T.C.F. 2001. Rendimento de carcaça, filé e subprodutos da filetagem da tilápia do Nilo, Oreochromis niloticus (L.), em função do peso corporal. Acta Scient. 23:897-901.

Tavares-Dias M. \& Faustino C.D. 1998. Parâmetros hematológicos da tilápia-do-Nilo Oreochromis niloticus (Cichlidae) em cultivo extensivo. Ars Vet. 14:254-263.

Tavares-Dias M. \& Sandrim E.F.S. 1998. Influence of anticoagulants and blood storage on hematological values in tambaqui, Colossoma macrosporum. Acta Scient. 20:151-155.

Tavares-Dias M. \& Sandrim E.F.S. 1999. Características hematológicas de teleósteos brasileiros. I. Série vermelha e dosagens de cortisol e glicose do plasma sangüíneo de espécimes de Colossoma macropomum em condições de cultivo. Acta Scient. 20:157-160.

Tavares-Dias M., Frascá-Scorvo C.M.D., Novato P.F.C. \& Moraes F.R. 2000a. Hematological characteristics of hybrid Florida red tilapia, Oreochromis urolepis hornorun $\mathrm{x} O$. mossambicus under intensive rearing. Anais $5^{\text {th }}$ Internatrional Symposium on Tilapia Aquaculture, Rio de Janeiro, p.533-541.

Tavares-Dias M., Schalch S.H.C., Martins M.L. \& Moraes F.R. 2000b. Características hematológicas de Oreochromis niloticus (Osteichthyes: Cichlidae) cultivadas intensivamente em "pesque-pague" do município de Franca, São Paulo, Brasil. Ars Vet. 16:76-82.

Tavares-Dias M., Sandrim E.F.S., Moraes F.R. \& Carneiro P.C.F. 2001. Physiological responses of "tambaqui" Colossoma macropomum (Characidae) to acute stress. Bolm Inst. Pesca. 27:43-48.

Tavares-Dias M. \& Moraes F.R. 2003. Características hematológicas da Tilapia rendalli Boulenger, 1896 (Osteichthyes: Cichlidae) capturada em "pesque-pague" de Franca. São Paulo, Brasil. Biosci. J. 19:107-114. 
Tavares-Dias M. \& Moraes F.R. 2004. Hematologia de peixes teleósteos. Villimpress, Ribeirão Preto. 144p.

Trinder P. 1969. Annals Clin. Biochem., London, 6:24-27.

Ueda I.K., Egami M.I., Sasso W.S. \& Matushima E.R. 1997. Estudos hematológicos em Oreochromis niloticus (Linnaeus, 1758) (Cichlidae, Teleostei). Parte I. Braz. J. Vet. Res. Anim. Sci. 34:270-275.

Vazzana M., Cammarata M., Cooper E.L. \& Parrinello N. 2002. Confinement stress in sea bass (Dicentrarchus labrax) depresses peritoneal leukocyte cytotoxicity. Aquacult. 210:231-243.

Wedemeyer G.A., Barton B.A. \& Mcleavy D.J. 1990. Stress and acclimation, p.451-490. In: Schreck C.B. \& Moyle P.B. (Eds), Methods for Fish Biology. American Fisheries Society, Bethesda.
Wenderlaar Bonga S.E. 1997. The stress response in fish. Physiol. Rev. 77:591-625.

Wepener V., Vuren J.H.J. \& Preez H.H. 1992. The effect of manganese and iron at a neutral and acid $\mathrm{pH}$ on the haematology of the banded tilapia (Tilapia sparrmanii). Bull. Environ. Contam. Toxicol. 49:613-619.

Wintrobe M.M. 1934. Variations on the size and hemoglobin content of erythrocytes in the blood various vertebrates. Folia Haematol. 5:3249 .

Yildiz H.Y. \& Pulatsü S. 1999. Evaluation of the secondary stress response in healthy Nile tilapia (Oreochromis niloticus L.) after treatment with a mixture of formalin, malachite green and methylen blue. Aquac. Res. $30: 379-383$ 